\title{
PARENTAL STRATEGIES AND ADOLESCENTS' PROBLEM BEHAVIOUR IN SCHOOL ENVIRONMENT: THE MEDIATION EFFECT OF RULES INTERNALIZATION
}

\author{
Ondrej Kalina, \& Maria Bacikova \\ Department of Educational Psychology \& Health Psychology, Faculty of Arts, \\ PJ Safarik University in Kosice (Slovakia)
}

\begin{abstract}
Research regarding parent-child processes has demonstrated that rules set up by parents towards their children plays protective role in problem behaviour in school environment. However, recent studies have revealed inconsistent associations among parental strategies which parents used to set up the rules and adolescents' problem behaviour. This study explores two different parenting strategies of rules setting to test the hypothesis that an autonomy-supportive strategy would relate negatively, whereas controlling strategy would relate positively, to adolescents problem behaviour. Moreover, mediation analyse was explored to test whether associations among parenting strategies and adolescents' problem behaviour could be explained by level of internalization of parental rules.

A cross-sectional representative dataset from elementary schools was used $(\mathrm{N}=581, \mathrm{M}=13.5$ years, $\mathrm{SD}$ $=0.59,51.7 \%$ of boys). Problem behaviour of adolescent were measured by 21 items scale (e.g. "Did you take something what did not belongs to you?"). Two types of parental strategies were explored: (1) autonomy - supportive strategy was measured by 7 items scale (e.g. "My father/mother allows me to make decision by my own"); (2) controlling strategy was measured by 8 items scale (e.g."My father/mother reminds me my previous mistakes whet criticizing me"). Internalization of parenting rules was assessed by 22 items questionnaire which consist from four separate scales (1) identification; (2) introjection; (3) external regulation and (4) rebellion. Linear regression models and mediation analyses were used for data analysis in SPSS 21.

As it was predicated the parenting strategies were significantly associated with level of problem behaviour of adolescents. Higher autonomy-supportive strategy by mother and father was related with less problem behaviour $(\mathrm{B}=-0.124 *$ in mothers; $\mathrm{B}=-0.147 *$ in fathers). On the other hand, higher controlling strategy by mother and father was related to higher rates of problem behaviour $(\mathrm{B}=0.172 *$ in mothers, $\mathrm{B}=0.201 *$ in fathers). The association among autonomy - supportive strategy and problem behaviour was partially mediated by identification $(-1.461 * * *)$ and by introjection $(-0.0721 *)$. The association among controlling strategy and problem behaviour was partially mediated by rebellion $\left(0.0953^{* * *}\right)$.

The results of this study point to importance of parental strategies in adolescence period as autonomy and controlling ways of setting rules may have opposite effect on problem behaviour. Moreover, both strategies impact the processes of rules internalization (identification, introjection and rebellion) which seems to be very important in this context.
\end{abstract}

Keywords: Internalization, problem behaviour, parental strategies, psychological control.

\section{Introduction}

Problem behaviour of Slovak school aged children has increased in recent years. The international study on teaching and learning by OECD (Jensen et al. 2012) has given alarming results in terms of school pupils' behavior. Teachers in participating countries of the study has reported late arrivals (39.4\%; in Slovakia: 13\%) and absence of students (45.8\%; in Slovakia: 39.8\%). Given the absence and late arrival of pupils, the situation of Slovak teachers compared to the international average appears to be more flattering. However, other aspects of the discipline are to the detriment of Slovak school pupils. Compared to the international average, Slovak school teachers are more often confronted with distracting pupils during their lessons, their lies and cheating, vulgarism or the destruction of school furniture. 
There is no doubt about the increase in non-discipline in schools, but it should be borne in mind that the issue of discipline goes beyond the institution of the school, because the level of discipline reflects the social situation. Discipline at school is to some extent a mirrored reflection of discipline in society and family in particular. School and society in this sense represent continuous vessels (Bendl, 2001). But what is the society that produces an increasing number of problem behavior pupils other than "previous" society? On such question, there can be multiple answers, and one of them is the nature of the relationship, which is no longer based on the asymmetry of the "superior and subordinate" relationship compared to traditional society and family as well. The relationship between a child and adults (parents) is based on partnership in a democratic structure and the child's obedience is then more difficult to claim.

The most frequents parental strategy is rules implementation in various context of child behaviour. Several different personality theories converge to suggestion that internalization of parental rules is an important determinant of the likelihood that parental rules will result in desired outcomes (Deci \& Ryan, 2000; Grusec \& Goodnow, 1994; Kochanska, 2002). Internalization is generally described as individual, active process through which external regulations is transformed into personally held values and through which they may integrate regulations into the self (Deci, Eghrari, Patrick, \& Leone, 1994). The Self-determination theory distinct three levels of internalized form of behavioural: (1) external regulation, behaviour is characterized only to comply with an external demands in order to get a reward or to avoid a punishment therefore individuals may perceive pressure and control to comply with an externally imposed rules (e.g. children may follow their parents' guidelines regarding problem behaviour to avoid parental punishment); (2) introjected regulation, in often characterized as motivation from an internalized pressuring voice as the source of motivation for behaviour is guilt, shame or worry (Assor, Vansteenkiste, \& Kaplan, 2009). For instance, adolescents may follow parental guidelines for problem behaviour domains to avoid feeling guilty about their behaviour; (3) identified regulation, in which person has personally identified with the importance of a behaviour and accepted it as a regulation of her own. E.g. adolescents follow parental rules regarding problem behaviour because they understand why their parents ask them to do so and because they view their behaviour as conducive to their self-endorsed goals.

Self-determination theory also propose that a lack of internalization and the behavioural problems associated with such a lack may increase controlling and decrease autonomy-supportive parenting (Grolnick, 2003). Parents usually prohibit their child from numerous types of problems behaviours by threatening to punish the child or by withdrawing privileges. Moreover, parents also use emotional type of pressure as they appeal to the child's feelings of guilt and shame or by limiting their love and acceptance when the child does not follow the rules. These types of covert control are consistent with the concept of psychological control (Assor, Roth, \& Deci, 2004; Soenens, Vansteenkiste, Luyten, Duriez, \& Goossens, 2005). In contrast to controlling styles of prohibition, parents may use an autonomysupportive style of prohibition, as they take the adolescent's frame of reference and provide a relevant and clear rationale for prohibition while also minimizing pressure (Deci et al., 1994).

We expected that adolescents in this study would be more likely to internalize their parents' rules regarding problem behaviour when they perceive their parents using an autonomy-supportive style. In other words, an autonomy-supportive style is facilitative of the process of internalization and thus would be associated with identified regulation. In contrast, we expect that adolescents in this study would be less likely to internalize parental rules when parents will use a controlling style. A controlling style of prohibition would thus foster more controlled and less internalized reasons for adopting parents' guidelines regarding problem behaviour.

Therefore the aim of this study is to explore the association among two types of parental strategies and problem behaviour of adolescent in schools. We also expect that rules internalization will mediate this relationship.

\section{Methods}

\subsection{Sample}

Participants were recruited from the national project VEGA focused on parental processes in context of health risky behaviour of adolescents. This analysis is based on data from 581 (51.1\% males; mean age $=13.5 ; \mathrm{SD}=0.65)$ students from 12 basic school from Slovakia.

\subsection{Measures}

Problem behaviour of adolescent as outcome variable was measured by 21 items scale (e.g. "Did you take something what did not belongs to you?') as each respondent indicate the answer on first 18 items on five point scale and last three items on four point scale. The score ranges from 21 to 106 point as 
the higher score indicates higher level of problem behaviour. Cronbach's alpha for problem behaviour was 0.840 .

Two types of parental strategies were explored:

(1) autonomy-supportive strategy was measured by 7 items scale (e.g. "My father/mother allows me to make decision by my own") using the Autonomy Support Scale of the Perceptions of Parents Scale (Grolnick, Ryan, \& Deci, 1991). The score ranges from 7 to 35 points as the higher score indicates higher level of autonomy-supportive strategy. The sum scores were computed separately for mother and father. Cronbach's alpha for autonomy-supportive strategy was 0.527 .

(2) controlling strategy was measured by 8 items scale (e.g."My father/mother reminds me my previous mistakes whet criticizing me") using Psychological Control Scale-Youth Self-Report (Barber, 1996). The score ranges from 8 to 40 points as the higher score indicates higher level of controlling strategy. The sum scores were computed separately for mother and father. Cronbach's alpha for controlling strategy was 0.747 .

Internalization of parenting rules was assessed by Internalization of parental rules in the moral domain (Soenens, Vansteenkiste, 2009) 22 questionnaire which consist from four separate scales for (1) identification; (2) introjection; (3) external regulation and (4) rebellion. The sum scores were computed separately for mother and father. Cronbach's alphas for these scales ranges from 0.728 to 0.866 .

\subsection{Statistical analyses}

Firstly, we selected only those respondents which completely answered the questionnaire regarding problem behaviour and other explored variables. After that using regression models we explored whether types of parental strategies were associated with problem behaviour of their children and similarly we explored whether type of internalization of rules will mediate this relationship.

\section{Results}

As it was predicated the parenting strategies were significantly associated with level of problem behaviour of adolescents. Higher autonomy-supportive strategy by mother and father was related with less problem behaviour ( $\mathrm{B}=-0.124^{*}$ in mothers; $\mathrm{B}=-0.147^{*}$ in fathers). On the other hand, higher controlling strategy by mother and father was related to higher rates of problem behaviour $(\mathrm{B}=0.172 *$ in mothers, $\mathrm{B}=0.201^{*}$ in fathers). The association among autonomy - supportive strategy and problem behaviour was partially mediated by identification $(-1.461 * * *)$ and by introjection $(-0.0721 *)$. The association among controlling strategy and problem behaviour was partially mediated by rebellion $\left(0.0953^{* * *}\right)$.

\section{Discussion and conclusion}

The results of this study point to importance of parental strategies in adolescence period as autonomy and controlling ways of setting rules may have opposite effect on problem behaviour. Moreover, both strategies impact the processes of rules internalization (identification, introjection and rebellion) which seems to be very important in this context.

\section{Acknowledgements}

This work was supported by the Slovak Research and Development Agency under the contract No. APVV-15-0662 and0253-11 and the Slovak Academy of Sciences under Contract No. VEGA $1 / 0623 / 17$.

\section{References}

Assor A, Roth G, Deci EL. (2004). The emotional costs of parents' conditional regard: A selfdetermination theory analysis. Journal of Personality, 72, 47-88.

Assor A, Vansteenkiste M, Kaplan A. (2009). Approach and avoidance introjected motivations: Approach is better than avoidance, but identified motivation is better than both. Journal of Educational Psychology, 101, 482-497.

Bendl, S. (2005). Ukaznena trida. Prague: Triton. 
Deci, E. L., \& Ryan, R. M. (2000). The "what" and "why" of goal pursuits: Human needs and the selfdetermination of behavior. Psychological Inquiry, 11 ,227-268.

Deci EL, Eghrari H, Patrick BC, Leone DR. (1994). Facilitating internalization: The self-determination theory perspective. Journal of Personality, 62, 119-142.

Grolnick WS. (2003). The psychology of parental control: How well-meant parenting backfires. Mahwah, NJ: Erlbaum.

Grolnick WS, Ryan RM, Deci E. (1991). Inner resources for school achievement: Motivational mediators of children's perceptions of their parents. Journal of Educational Psychology, 83, 508-517.

Grusec JE, Goodnow JJ. (1994). Impact of parental discipline methods on the child's internalization of values: A reconceptualization of current points of view. Developmental Psychology, 30, 4-19.

Jensen B, et al. (2012). The Experience of New Teachers: Results from TALIS 2008, OECD Publishing. http://dx.doi.org/10.1787/9789264120952-en

Kochanska, G. (2002). Committed compliance, moral self, and internalization: A mediational model. Developmental Psychology, 38, 339-351.

Barber, BK. (1996). Parental psychological control: Revisiting a neglected construct. Child Development, 67, 3296-3319.

Soenens B, Vansteenkiste, M, Luyten P, Duriez B, Goossens, L. (2005). Maladaptive perfectionistic self-representations: The mediational link between psychological control and adjustment. Personality and Individual Differences, 38, 487-498. 